\title{
"Authentically" Effeminate? Bialystok's Theorization of Authenticity, Gay Male Femmephobia, and Personal Identity
}

\author{
Adam W.J. Davies
}

\begin{abstract}
Authenticity is a commonly heralded ideal in Western modernist discourses, with a large amount of literature describing individuals' personal journeys towards selffulfillment (Bialystok, 2009, 2013, 2015, 2017; Taylor, 1991; Varga, 2014). This paper examines Lauren Bialystok's (2013) conception of authenticity in sex/gender identity and proposes that effeminate or 'femme' gay men make a strong case for fitting within such a conception of authenticity. Effeminate gay men experience significant in-group discrimination within gay men's communities, with many gay men "defeminizing" (Taywaditep, 2002) themselves upon entering adulthood and mainstream gay communities. Through this exploration of Bialystok's (2013) model for authenticity in sex/gender identity and the identity-based challenges effeminate or femme gay men experience, this paper describes why effeminate gay men fit Bialystok's model, and the ethical dilemmas of theorizing authenticity in personal identity (Bialystok, 2009, 2011). Providing supportive and positive early environments in school while specifically addressing gender-based discrimination in childhood provides more opportunities for positive identity development and the potential of fulfilling selfauthenticity within gender identity for femme gay men.
\end{abstract}

Keywords: authenticity, personal identity, effeminacy, gay men, Lauren Bialystok, metaphysics

\footnotetext{
Adam W.J. Davies is currently an Assistant Professor at the University of Guelph in their Family Relations and Applied Nutrition Department. Adam holds a Master of Arts from the Ontario Institute for Studies in Education and is nearing completion of his Ph.D. in Curriculum Studies \& Teacher Development and Sexual Diversity Studies at the Ontario Institute for Studies in Education, University of Toronto. Adam's research interests are in queer and trans studies, gay men and masculinities, and critical disability studies. Adam has been published in Gender and Education and The Canadian Journal of Human Sexuality.
} 
Davies

\section{Introduction}

Within modernist discourses and philosophical debates, there is a fascination with authenticity and quests for self-actualization (Bauer, 2017; Bialystok, 2011, 2015, 2017; Taylor, 1991). Dilemmas of authenticity and personal identity are relevant for goals of self-fulfillment as debates continue around the metaphysical qualities of authenticity and its importance within philosophies of personal identity (Bialystok, 2009, 2013, 2014, 2015). What does it mean to possess a 'part' of you? How does one know if they are being authentic to such a 'part' of themselves? Such questions seem to be particularly relevant within the realm of gender identities as many individuals struggle to become 'authentic' to their sense of gendered self throughout their life course. Feminist philosopher, Lauren Bialystok (2013), delineates five components that must be met for any conception of authenticity, while specifically describing how these components apply to sex/gender identity. While delineating Bialystok's (2009, 2013) metaphysically essentialist theorization of authenticity in personal identity, this paper will engage with how this account of authenticity applies fittingly to the experience of effeminate or femme gay men ${ }^{1}$ and describe their experiences of gender-based marginalization within gay men's communities. Additionally, this paper will elaborate on a discussion of "defeminization" processes (Taywaditep, 2002) — which occur between adolescence and adulthood for many gay men — demonstrating how, for those gay men who choose to remain "true to themselves," these processes elicit significant gender-based discrimination and identity challenges. Thus, this paper will serve to both exemplify Bialystok's $(2009,2013)$ theorization of authenticity within the context of femme gay men, discuss the gender-based forms of discrimination experienced by gay men who do not "defeminize" by adulthood, and conclude by raising some questions regarding theorizing authenticity and personal identity and tensions between metaphysical essentialism and poststructural critiques.

\section{What is Authenticity?}

Authenticity has many differing definitions within the philosophical literature (Bauer, 2017; Bialystok, 2009; Oshana, 2007; Taylor, 1991). What is authenticity and what does it entail to be "truly" authentic? How does one achieve authenticity, or is it even possible to do so? Despite philosophical debates regarding the varying definitions of authenticity, there is still no clear-cut philosophical premise for authenticity (Bialystok, 2011, 2014, 2017). Bialystok (2013) defines authenticity in the context of personal identity as a "relation of the self to itself" and a "way of being" (p. 124). As one of the foundational philosophers on authenticity, Rousseau distinguished between the internal and external, claiming that authenticity is gleaned from an internal sense of self and that the interference of external influences can limit one's own authenticity (Bialystok, 2011, 2014; Taylor, 1991). As an expressivist, Rousseau believed in the importance of expressing

\footnotetext{
${ }^{1}$ Throughout this paper, I use 'effeminate' and 'femme' interchangeably, as many effeminate gay men specifically employ the gender identity, femme. Within queer and trans communities, there has been a recent increase in usage of femme as an identity label to signify an individual with traditionally 'feminine' gender traits in terms of aesthetic and personality. I also note how the term 'effeminate' has historically been viewed as a form 'failed masculinity', which can further gendered hierarchies and the cultural privileging of masculinity over femininity through its usage. Thus, while I use the term effeminate, I am critical of how it has been used to signify femininity as lower than masculinity (see Hoskin, 2017).
} 
one's inner essence on the outside and the necessity of one's true self being recognizable by others (Bialystok, 2011; Taylor, 1991; Varga, 2014). Writing during the Enlightenment, Rousseau's notions of authenticity depend upon a "true self" or an "inner essence," and his ideas call to mind notions of individualism, liberal autonomy, and self-understanding (Bialystok, 2014, 2017). Rousseau (1903/2012) writes, "I know my heart, and have studied mankind; I am not made like any one I have been acquainted with, perhaps like no one in existence; if not better, I at least claim originality" (p. 12). He (2006) later writes in his Lettres Morales, that "man's first idea is to separate himself from all that is not himself" (cited in Bialystok, 2014, p. 282). Embedded within this rhetoric is the notion that authenticity involves a relationship of an individual to themselves and their personal actions or behaviors (Bialystok, 2011, 2013, 2014, 2015). ${ }^{2}$

Meanwhile, other philosophers view Rousseau and romanticist conceptions of authenticity as too individualistic and posit more intersubjective accounts (Bialystok, 2011, 2015; Taylor, 1991). Charles Taylor (1991), for example, discusses the dialogical construction of identity. Authenticity, in Taylor's interpretation, includes a dialogic process of connection with a "wider whole" or "belonging to nature" (cited in Reisert, 2000, p. 310). Katharina Bauer (2017) has argued for "the relevance of the ideal of expressing one's individual personality and of the ideal of being a person in the Kantian sense for understanding the ethical ideal of authenticity" (p. 568). For Bauer (2017), ethics come into account for authenticity through a "critical self-reflection" and "sober and honest self-investigation" that characterizes a "continuous process of selfauthentication" (p. 578). This conceptualization of ethics in authenticity aligns well with Bialystok's (2014) explication of authenticity as “a convergence between a person's essence and her behavior, to the exclusion of those properties that are non-essential" (p. 281). Thus, one's behaviors must converge with one's "essence" through a continual process of self-authentication and self-investigation. This metaphysically essentialist approach to authenticity denotes an ontological thesis of an absolute truth; that is, there is an "essence" or an absolute "true self" which a person can be true to. Incommensurable with postmodern and poststructural accounts of truth, Bialystok's $(2009,2013)$ theorization of authenticity demands an inner self that one can be in a state of alignment with. Thus, there are ethical questions that emerge regarding the use of a metaphysically essentialist approach to authenticity in personal identity (Bialystok, 2009, 2011, 2013, 2017).

\section{Bialystok's Metaphysically Essentialist Theorization of Authenticity in Sex/Gender Identity}

Metaphysically essentialist approaches to authenticity consider authenticity the confluence of one's behaviors and "essence" or "true self" (Bialystok, 2009, 2013). Although hard to define, broadly speaking, metaphysics refers to the nature and origin of things - the cause of something (van Inwagen, 2007). While some approaches to authenticity are more existential, Bialystok's theorization of authenticity in sex/gender identity relies on a robust amount of metaphysical realism and an onto-epistemological status of a "true self" with which one's behaviors and actions overlap or align with (Bialystok, 2013, 2017). Bialystok's $(2009,2013)$ theorization follows a liberal ethic in which individuality is cultivated through self-reflection and authenticity in personal

\footnotetext{
${ }^{2}$ Please see Bialystok (2011, 2014), Varga (2014), and Taylor (1991) for a thorough examination of the Romanticist foundations of authenticity and Rousseau's influence on authenticity discourse.
} 
identity is achieved when one's "behavior converges with who [one] actually is" (Bialystok, 2014, p. 278). To discuss metaphysically essentialist approaches to authenticity, one must consider having a "true self", or a metaphysical approach to substance and identity, and acknowledge the coupling of one's identity, true self, and behaviors (Bialystok, 2009, p. 222). There is still debate over the philosophical definition of authenticity and the possibility and applicability of a metaphysically essentialist approach to authenticity, particularly in the realm of personal identities (Bialystok, 2009). Existential approaches to authenticity and personal identity have been critiqued by Bialystok (2009), who states, "[existentialism's] peculiar commitments rule out the possibility of doing justice to our intuitions about authenticity and personal identity," as "at the end of the analysis, [there is] no conclusion about who one is - one of the most foremost desiderata of an account of authenticity" (p. 93). This critique outlines the limitation of existentialist approaches to authenticity - there is no sense of acknowledgment of a person's intuitions and frameworks for who they are and why they choose to identify a certain way (Bialystok, 2009, 2014). If being authentic to a personal identity involves being true to an "inner self," there is a metaphysical argument for interiority (Bialystok, 2009, 2013).

In her chapter, "Authenticity and Trans Identity," Lauren Bialystok (2013) suggests five components of authenticity in a working model of a metaphysically essentialist approach to authenticity in gender identity. This model includes: (1) a metaphysically essentialist structure that acknowledges one's essence, or a component of the self that is vital to one's identity and can be juxtaposed with parts of our identity that are part of us, but not vital for our sense of identity; (2) the "essential" identity should be extended over a long period of time and be seen as a feature of one's character; ${ }^{3}$ (3) there must be a means of being "inauthentic"; that is, one must have various choices available that would entail dismissing an essential component of one's self; (4) authenticity should work against conformity in the sense of striving to make choices autonomously and based on one's own selfhood as much as possible; and, (5) there should be an understanding of how acting authentically provides specific value for an individual. Bialystok (2013) describes how this model for authenticity might provide an example of a metaphysically essentialist approach to authenticity within gender identity for trans ${ }^{4}$ individuals.

Based on Bialystok's (2013) theorization of a metaphysically essentialist model for authenticity in sex/gender identity, a strong argument can be made for the application of this model to effeminate or femme gay men. While the literature on authenticity is varied and extensive, there are important conversations regarding the various identity-based challenges effeminate and femme gay men experience within Western gay male cultures. For example, effeminate gay men (and gay men in general), often turn to gay male spaces and communities for support and belonging after coming out and declaring their sexual orientation. However, if upon doing so they experience further isolation due to their gender expression, considerations of authenticity must take into account the differential costs of such authenticity. This challenge calls for a necessary discussion regarding authenticity and embodiment and the ontological implications of a metaphysically essentialist approach to authenticity in sex/gender identity.

\footnotetext{
${ }^{3}$ Bialystok (2013) references Paul Ricoeur (1992) to define character as "the set of distinctive marks which permit the re-identification of a human individual as being the same" (p. 126).

${ }^{4}$ Here, I used "trans" to indicate those under the trans umbrella and purposefully leave out the asterisk based on recent criticisms from trans scholars themselves. Please see: http://www.transstudent.org/asterisk.
} 


\section{Authenticity, Gay Male Effeminacy and Bialystok's Theorization: An Exploration}

The discourse of authenticity is much employed within the context of Western liberal gender and sexual identities and activism (Bialystok, 2013, 2017). The situation of effeminate and femme gay men, authenticity, and personal identity is particularly ripe for analysis due to the high rates of discrimination effeminate and femme gay men experience, both within their respective sexual communities and society at large (Bergling, 2002, 2006; Eguchi, 2011; Miller, 2015, 2018; Miller \& Behm-Morawitz, 2016; Sánchez, Greenberg, Liu, \& Vilain, 2009; Taywaditep, 2002). Hale and Ojeda (2018) write, "This dual desire in popular gay male discourse to be masculine and to have masc credentials has the effect of reproducing a widespread denigration of femininity in other gay men, and has at its centre a fundamental hostility to, disinterest in, and denigration of, women" (p. 7). This gay male cultural privileging of hegemonic masculinity lends to antifemininity attitudes and a communal denigration of effeminate men or men deemed "fem" (leading to the popular "no fems" or "masculine guys only" statements on online dating and hook-up applications for men seeking men) (see Miller, 2015). However, due to the cultural normalization of femmephobia (Serano, 2007/2016) ${ }^{5}$ and misogyny in queer communities, many individuals are increasingly identifying as femme to express their embracement of femininity, despite cultural privileging of masculine gender expression within queer and trans communities (Blair \& Hoskin, 2015, 2016; Serano, 2012; Taylor, 2018).

For Bialystok's first requirement of a metaphysically essentialist structure that contains a "self" which is vital to one's identity, the narratives of effeminate gay men speak to how their effeminacy is vital to a sense of authenticity to their identity and themselves, despite the cultural and social denigration they experience within gay male cultures. Huffington Post blogger Jeremy Alexander (2016) writes about his own experiences with femmephobia, saying,

Strangely enough, being seen as 'straight acting' ${ }^{6}$ is something desired by a large demographic of gay men, hoping to embody these traits of the heterosexual male...All I know is that I'm thankful I grew up with supportive parents that let me grow into who I was meant to be, telling me it was OK to like playing with dolls rather than action figures and reassuring me that my love for Sailor Moon was totally valid for a boy.

Here, Alexander references an inner sense of self that directed his actions and choices during childhood to assist him in developing his sense of identity as an adult. Within the narratives of effeminate gay men, stories of refusing to conform to both society and the propagated norms of gay culture speak to calls for authenticity.

\footnotetext{
${ }^{5}$ Femmephobia can be defined as the systemic devaluation of all that is associated with femininity. While discussions of femmephobia have been accused of biological essentialism, I am not employing femmephobia in a biologically essentialist manner, nor am I making any specific claims that associate productions of femininity with any particular bodies. See Blair \& Hoskin (2016) and Serano (2007/2016) for more details.

6 The term "straight acting" or "acting straight" was coined in gay male communities to describe a gay man who conforms to dress, activities, and gender expression that can be perceived as being masculine (Sánchez \& Vilain, 2012).
} 
For many gay men, conforming to hyper masculinized gendered norms becomes a means of assimilation and survival in a community where femininity and effeminacy are treated with hostility (Hale \& Ojeda, 2018; Martino, 2006; Sánchez, Greenberg, Liu \& Vilain, 2009). For effeminate and femme gay men, the choice to remain feminine in gender expression and/or to identify as femme involves actively choosing to retain one's femininity despite communal pressures for masculinized conformity. For example, in the Huffington Post posting, "Men Are Gay Because They Like Men.' Femmephobia and Sizeism in the Gay Community,' Jason Wimberley (2015) describes being informed in a gay bar by another gay man, "You know, men are gay because they like men. You should think about putting on a little muscle next time." While Jason felt he had been gay his "whole life," he started taking testosterone supplements to increase his muscle mass, turning his body into a "wreck." Eventually he realized, "[W]e gotta be ourselves, you can't let someone else tell you who you need to be. Whether it's too big or too little or with tights and lip gloss, you do what you need to do." Jason's story suggests he, too, feels a sense of inner self-hood that pulls him to exhibit his masculinity in a way that defies gendered scripts and masculine norms.

In drawing attention to the body, it is worth recognizing how it can be representative of one's sense of self and how embodiment can relate to authenticity. With masculinized and muscular forms of embodiment highly privileged within gay male communities (Alvarez, 2008; Levine, 1998; Miller, 2018), I would like to draw attention to not only the importance of one's essence in gendered authenticity, and one's "true" identity, but also the importance for considering embodiment in authenticity and gender identity as well. How does the body and what it represents factor into authenticity in gender identity? Sociologist Nick Crossley (2006, p. 21) writes of forms of "reflexive embodiment," defined by Hutson (2010) as "the precondition for appearance and identity, as individuals must simultaneously reflect on their body-as-subject and body-as-object before announcing an identity through appearance" (p. 218). For effeminate gay men, their embodiment of femininity exemplifies how, despite the potential for aspiring for dominant forms of masculinized embodiment, the body can be a signifier of gendered identity and a refusal to conform, denoting a sense of authenticity to one's gendered self.

Hutson's (2010) qualitative study of authenticity and embodiment in gay men and lesbians after coming out delineates how, for many gay men, gaining acceptance and belonging in gay spaces is often accompanied by a compulsion to conform to body building cultures while wearing tight fitting clothing. Referencing the glorification of masculinity and gym cultures in gay communities, Hutson (2010) writes, "This hypermasculinization leads many to hypermuscularization and materializes through an expectation of gym going and muscle tone" (p. 224, emphasis added). Thus, despite masculinized and muscular bodies holding erotic and sexual capital in gay male communities, many effeminate men actively choose to retain their embodiment despite outside pressures and alternative options. This exemplifies Bialystok's postulation that authenticity to the self must involve choosing one's self amongst alternative options which would involve a dismissal of an essential part of one's existence. Just as Bialystok (2013) argues that for trans individuals, authenticity can (but does not always) arise from having their outer appearance 
altered to align with their sense of self, ${ }^{7}$ for effeminate gay men, their sense of authenticity often arises from not altering their outer appearance in order to remain true to their inner sense of self.

Conditions of femmephobia within gay male communities present a conflicting situation for many effeminate and femme gay men. If they regard being gay and finding a sense of belonging in a common gay community as a core part of their sexual identity, but also perceive their effeminacy as either a core or unchangeable component of their gender identity and expression, they must often choose conformity or discrimination within gay communities. Notably, steroid use and hormone injection are highly prevalent in segments of gay male communities (Griffiths, Murray, Dunn \& Blashill, 2017; Halkitis, Moeller \& DeRaleau, 2008; Sánchez, Greenberg, Liu, \& Vilain, 2009), as is gendered surveillance in exclusively gay spaces, otherwise known as the "queer gaze" (Wray, 2003). Consequently, gay men who remain effeminate in gender expression and behaviors are likely to have a strong essential sense of self, particularly under situations of such scrutinization and femmephobia. ${ }^{8}$ Just as Humanities scholar Jay Prosser (2006, cited in Bialystok, 2013, p. 129) describes how trans individuals can have a sense of "corporeal interiority," in which they have an inner sense of identity despite outer pressures to confirm to gendered norms and appearances, it can be suggested that effeminate gay men have a strong inner sense of self in the same way that pushes them to retain their gender expression/identity despite outer pressures from both heterosexist society and gay culture to conform to masculine norms. ${ }^{9}$

Effeminate gay men also fit Bialystok's emphasis on working against conformity and a reliance on knowledge from the self, through their refusal to "masculinize" or "defeminize" themselves, despite pressures from both within gay male communities and society at large. Barry and Martin's (2016) research provides an example of a participant who experienced clashes in identity positions between his gender fluid and femme aesthetic, and the hyper-masculine expectations of gay culture and dating applications and websites.

While his "gender fluid" mode of dress feels more "natural and authentic," it also causes frustrations when engaging in broader gay culture. He gave the example of dating apps and explains, "There's no way to navigate apps like Grindr if you don't belong to the norm [...] You have to appear and dress cisgendered to be successful" (p. 239).

Metaphysically consistent with several interpretations of authenticity in identity (e.g., Bialystok, Taylor), the ethics of authenticity require a certain degree of individualism and being true to one's self or essence. Despite pressures to conform from both society at large and the norms of gay spaces_-including gay male social networking applications like Grindr-effeminate gay men feel

\footnotetext{
${ }^{7}$ For a thorough discussion of transnormativity and the medicalization of trans bodies, please see Vipond (2015). I note how many trans individuals actively resist the medicalization and alteration of their bodies by medical regimes. ${ }^{8}$ I make this statement considering the research that suggests how gay men are more gender nonconforming during childhood, while striving to ascertain masculine norms during adolescence and adulthood (see Taywaditep 2002), as well as the research that discusses hyper-masculine norms and gendered surveillance being entrenched in gay spaces, particularly gay online applications (Miller \& Behm-Morawitz, 2016).

${ }^{9}$ I would also like to note that I am not equating the experience of trans individuals with cisgender effeminate gay men. The journey to authenticity and selfhood for trans individuals and the medicalization of their bodies is still very different than the lived experience of cisgender effeminate gay men resisting masculinizing their embodiment.
} 
more authentic in their aesthetic and gendered presentation, despite experiencing isolation and exclusion due to their self-expression.

Calls for autonomy from masculinized gay norms and resistances from exaggerated forms of masculinity ring true as many queer and trans individuals embody the form of gender expression and identity that "feels right" for them. Trans-feminist writer Julia Serano (2012) states,

So, although you can make the case that masculinity and femininity are "performances," for me, feminine expression feels more natural. It resonates with my sense of self in a way that I do not really have words to describe. It just feels right to me, whereas masculine expression always felt wrong (p. 179).

While acknowledging the socially constructed nature of gender, Serano (2012) also speaks to how femininity "feels right" to her; that is, there is still a "self" who chooses to embody these socially constructed norms. Autonomy has been theorized in relation to authenticity, but "the standard view of authenticity demands more than is necessary for a plausible account of autonomy vis-à-vis one's choices and actions" (Oshana, 2007, p. 428). There is a degree of autonomy that is required when theorizing authenticity, but the ethical limits of such autonomy, or when exactly one is responsible to a collective community or identity, is unclear.

In regard to Bialystok's final component of authenticity, the value of authenticity to an individual, the quoted narratives in this paper and the resiliency of effeminate gay men makes the personal value and importance of authenticity crystal clear. Living in a state of authenticity to one's sense of self while experiencing difficulties with in-group discrimination and outside marginalization allows these men to cultivate their own unique and authentic forms of gendered expression. This perseverance to convey masculinities that differ from the hegemonic norm can be theorized to exist from an inner sense of self that is authentic to each of these men. Effeminacy, in itself, has numerous iterations and conceptions, and as such, these men are finding individual and unique ways of expressing and/or identifying their gender. Thus, the importance of gender expression and identity as a continuation of one's sense of self and identity is crucial to acknowledge, as are the personality traits and aesthetic features that are ascribed to various gender identities. Authenticity as a state of convergence between one's essence and their behavior (Bialystok, 2009, p. 28) is strongly exemplified in the narratives of these effeminate men. With this definition of authenticity, it can be argued that effeminate men conceive their gender identity and expression to be an essential component of their essence or self, without them being gender essentialist themselves or thinking in strict gender binaries (Bialystok, 2013, p. 128; 2016).

\section{Authenticity, Gay Youth, and "Defeminization"}

The societal gender norms and scripts that govern and regulate expressions of effeminacy within young boys and adolescents propagate shame for gender-nonconforming youth who feel outside of the norm and experience gender-based discrimination (Allan, 2016; Downs, 2012; Sedgwick, 1994). For many gay-identified men, adolescent expressions of effeminacy often dissipate upon entering gay men's cultures and communities due to experiences of femmephobia from other gay men (Bergling, 2002). Taywaditep's (2002) study of the anti-effeminacy attitudes of a sample of gay men discusses the phenomenon of gay men - who were often gender non- 
conforming during childhood-engaging in a process of "defeminization" during adolescence, such that they subsequently enter gay life as gender-conforming adults (p. 5). Taywaditep (2002) articulates how "Ironically, gender-nonconforming gay men may suffer from discrimination not from society at large, but from other gay men, who are most likely to have experienced stigmatization and may have been effeminate earlier in their lives" (p. 7). Taywaditep's (2002) research illustrates how anti-effeminacy and femmephobic attitudes in gay men develop through their own processes of "defeminizing." Thus, for men who retain their effeminacy and exhibit it openly in adulthood, or who identify as femme, this sense of authenticity and personal identity can be deemed a long-term and continuous feature.

Questions of personal authenticity and belonging arise for both effeminate adolescents and gay men, as the common practice of "defeminzation" for many gay men between adolescence and adulthood relates to discussions of authenticity. For Bialystok, authenticity in gender identity requires a continuity over an extended period and also the possibility of being inauthentic. Many gay men masculinize or "defeminize" themselves upon entering adulthood to present themselves as heterosexual within everyday society, thereby formulating gender hierarchies within gay communities that position effeminate gay men as undesirable and deviant (Connell, 1992; Martino, 2006). Ethical questions of authenticity arise with the glorification of hegemonic masculinities in gay communities, as the pressure to masculinize one's self-expression and privilege emotional and aesthetic norms deemed "masculine" can lead to psychological impacts for both effeminate gay men and men who aspire to meet these norms (Sánchez, Greenberg, Liu \& Vilain, 2009).

Fischgrund, Halkitis, and Carroll (2012) explicate how hegemonic norms for masculinities within gay men's communities strongly impact the mental health of gay men, with recommendations for reframing how masculinities are constructed and constituted within gay communities to lessen the psychological and social pressures to engage with dominant norms for masculinity. In their study of non-heterosexual identifying men's perspectives of drag queens, Bishop, Kiss, Morrison, Rushe, and Specht (2014) delineate how many gay men hold negative perceptions of drag queens, particularly in regards to the drag queens' respective gender expression and perceived femininity. These negative views can affect drag queens' sense of community and belonging in mainstream gay cultures. As explored in Cadwell's (2009) study of the role of shame in shaping gay men's gender and sexual selves, this denigration of effeminacy within gay men comes from childhoods of experiencing gender policing from adult figures and continual aspirations to be loved and accepted by parents and guardians. Although the pressure to conform to hegemonic conceptions of masculinities affects all men, Cadwell (2009) describes how "for gay men in particular, any hint of vulnerability can be quickly shamed as fem, mama's boy, sissy" (p. 200). Such pressures often result in the in-group denigration of emotional vulnerability and sensitivity amongst gay men due to these traits being deemed feminine and "weak."

Effeminacy in young boys is commonly psychologically pathologized (Sedgwick, 1994), with a multitude of psychological studies invested in "male transsexualism" (Stoller, 1968) or "defeminization and adult well being" (Harry, 1983). The medical history of psychologization and pathologization of childhood and adolescent effeminacy in boys conflates expressions of male effeminacy and homosexuality, as Kuhl and Martino (2018) explicate: "Men who exhibited identifiably effeminate mannerisms and behaviors were easily pathologized as gender inverts and became readily stigmatized and visibilized as homosexuals with pejorative associations of being 
failed men" (p. 33, emphasis in original). Trans-feminist writer Julia Serano (2007/2016) adds, "[there is a] societal obsession with critiquing and belittling feminine traits in males ... [which] encourages those who are socialized male to mystify femininity and to dehumanize those who are considered feminine, ...thus form[ing] the foundation of virtually all male expressions of misogyny" (p. 342). Serano's (2007/2016) explication of the continual pathologization and psychologization that effeminate men experience further speaks to how strongly effeminate gay men value their authentic gendered self.

Critical psychologist Jemma Tosh (2016) describes the societal concern over gender variance in young boys and the ramifications of the introduction of the medical diagnosis of childhood gender identity disorder' within the third edition of the Diagnostic and Statistical Manual of Mental Disorders. Such discourses continue to pathologize gender nonconformity in young boys as many people believe that "for a boy to be called 'sissy' can be devastating. It pierces a boy's self-image at its most vulnerable point” (Green, 1979, p. 1, as cited in Tosh, 2016, p. 58). Noting the continual violence and gender policing directed at young gender-nonconforming boys in schools (Martino, 2000; Pascoe, 2011), further supports are necessary to ensure the positive self-development of young boys in relation to their respective gendered selves and identities. American psychologist Alan Downs (2012) delineates the ways in which gay men commonly hide or mask their effeminacy during childhood to avoid gender policing and homophobia from peers. Downs (2012) writes,

And we didn't just hide ourselves from our parents. As best we could, we hid the truth from everyone. Children, probably more than any other people, are keenly aware of differences in one another, and often torment other children they perceive as different (p. 11).

For some gay men, experiences of gender policing and homophobia in childhood result in shame around effeminacy, which leads to both in-group and outside femmephobia as adults, and subsequent processes of defeminization. For schools to ensure the support of authentic genderidentity development and to combat gender hierarchies, anti-oppression projects should address gender-based discrimination explicitly and separate gender from anti-homophobia approaches. Lee Airton (2009) theorizes how school-based anti-homophobia approaches need to explicitly tackle genderism, or "the pervasive and systemic belief in the superiority of gender-normative as the only true and natural ways of being gendered" (p. 132). By combating genderism as it manifests in schools, space can be cultivated for young boys and men to express their gendered selves in ways that feel authentic to them, therefore crafting more inclusive LGBTQ+ communities for men in their adult lives.

Within the narratives of effeminate men, stories of being effeminate over a prolonged period despite bullying and discrimination during childhood echo the continued importance of effeminacy for their sense of self and identity. Vish Gaikwad (2015), a self-proclaimed effeminate gay man, writes in a commentary for The Advocate,

I've gone through struggles being an effeminate man - tireless worrying whether I'd be accepted by both gay and straight peers. I'm now at a point where people's 
opinions don't matter. I'm striving to be authentically me, and a great part of that is accepting my femininity.

Through these narratives, these men reference a self to be true to and a component of personhood that requires the expression of one's gendered self. Just as Jeremy Alexander described how his parents' support provided a space for him to express himself genuinely, it is necessary to cultivate environments where young boys feel that they can be supported in their identity development. By providing more inclusive school and home environments for gender diversity, less shame and stigmatization will emerge around effeminacy, translating into less pressure for effeminate gay men to defeminize as they approach adulthood. While not all gay men envision themselves as femme or effeminate in self-presentation, further space can be crafted for effeminate men to express themselves authentically.

\section{Debates in Authenticity and Personal Identity}

Considering Bialystok's theorization of authenticity in sex/gender identity, it is necessary to discuss some of the ethical questions and debates that emerge in conversations of authenticity, particularly noting the metaphysically essentialist foundations of Bialystok's model. With the emergence of effeminate men and other queer and trans individuals identifying as femme, does personal identity matter, is it important, and what are some of the ethics of personal identity and authenticity under poststructural scrutiny? For many individuals, their sex/gender identity is of great importance, especially for those who are seeking a sense of personal authenticity, or a feeling that "this is me" in how they express their gendered self (Bialystok, 2009, 2011, 2013). Philosopher, Derek Parfit (1984) notes, "If we believe that we are separately existing entities, we could plausibly claim that identity is what matters. On this view, personal identity is a deep further fact" (p. 262). Importantly, in order to claim authenticity to a personal identity, this process must involve a deeply personal and individual form of introspection. Bialystok (2011) writes, "authenticity is a form of alignment or consistency within the self, which requires self-knowledge (or its pursuit) to be actualized" (p. 208). If personal identity does not matter or exist, it does not make sense to discuss how to be authentic to such an identity (Bialystok, 2011).

With the continued rise of gay men identifying as femme to declare their sense of gendered authenticity-despite in-group and societal discrimination - there is an argument for a consideration for the importance of personal identity, particularly as it pertains to sex/gender identity. To suggest metaphysical essentialism denotes a semblance of an a priori self to be discovered (Bialystok, 2009). Bialystok (2011) writes, "If there is no identity (gender or otherwise) separate from its social performance or construction, it becomes nonsensical to talk about the convergence between one's identity or true self and one's behavior" (p. 222). This positing of an a priori self implies a liberal humanist ethic in which one considers one's self a location of rational consciousness. Liberal humanism has received considerable critique from poststructuralists (Butler, 1990; Foucault, 1970; Rose, 1998; Titchkosky, 2014) and critical race scholars (Wynter, 2003). In a critique of liberal Enlightenment-based humanism, decolonial theorist Aimé Césaire 
(2001) notes, "At the very time when it most often mouths the word, the West has never been further from being able to live a true humanism - a humanism made to the measure of the world" (p. 73). Thus, ethical questions arise whether debates of authenticity should be discussed if they metaphysically demand a universal form of liberal humanism which is exclusionary in nature. This requires an analysis of when authenticity discourse is being used and how it is being deployed to understand when it might be a metaphysical possibility to be "true to yourself" (Bialystok, 2014, personal communication).

Black feminist bell hooks (1992) writes how discourses of authenticity and essentialism reify tropes of black women as victims within white imaginaries. hooks (1992) writes of her own experience,

My story was reduced to a competing narrative, one that was seen as trying to divert attention from the 'true' telling of black female experience. In this gathering, black female identity was made synonymous again and again with "victimization." The black female voice that was deemed "authentic" was the voice in pain (p. 44).

hooks' writing illustrates a danger in discussions of authenticity. Specifically, it points out how identifying an "authentic" experience in relationship to race can work to dangerously reify white supremacist and anti-black ideologies. Additionally, poststructural feminist Patti Lather (2000) in the context of poststructural critiques of ethnographic research-writes, "Questions of authenticity and voice are at claims to the "real' in ethnography" as "At risk is a romance of the speaking subject and a metaphysics of presence that threaten to collapse ethnography under the weight of identity, intentionality, and selective appropriation" (p. 20). Under poststructural critique, both authenticity and personal identity could be considered modernist inventions that hold great epistemological danger in terms of reification and reliance on a liberal humanist mode of representation.

Still, authenticity is heralded for its alignment with 'truthfulness,' however uncritical or problematic such heralding might be (Bialystok, 2011, 2015). In the case of effeminate or femme gay men, such forms of authenticity to the 'self' can be considered acts of resiliency against gay male cultures and heterosexist society, both of which denigrate femininity in men. Degrazia (2004) describes how, "The sense of personal identity at the heart of authenticity and self-creation is that connected with our self-conceptions, what we consider most important to who we are, and our self-told narratives about our own lives" (p. 37). For those who have experienced great harm and marginalization due to their sense of gendered self, their personal identity and identification with femininity matters a great deal in honoring their individual identifications with gender.

As well, if personal identity and authenticity do not matter, this can risk disqualifying individuals' experiences with a specific sense of gender identity throughout their lifetime. Monro (2005) writes that, while "[Judith] Butler and other poststructuralists account for the psychic constitution of the self, they fail to satisfactorily explain notions of self-essentialism. It is not enough to dismiss these as false consciousness, as this denies people's lived experiences" (p. 9). This is where poststructural critiques come into conflict with claims to lived experience, as denying someone's sense of gendered authenticity can disregard their lived experiences with gender and self-knowledge. For many effeminate or femme gay men, experiences of gender policing and 
gender-based violence can leave serious psychological damage and ramifications. To deny one their sense of 'authenticity' and self-hood can cause further harm. However, on an epistemological level, in order for there to be a "self" to be true to, there has to be the presence of a "self" in a metaphysical form to begin with (Bialystok, 2009, 2011). Such 'metaphysics of substance' are looked at with skepticism by poststructuralists, as the self that is often constructed under liberal theories epistemologically favors Enlightenment-based, white, male, heterosexual, and ablebodied subjects (see Rose, 1998; Titchkosky, 2014; Wynter, 2003).

Bialystok (2014), herself, is also skeptical of the metaphysical possibilities of fulfilling a complete account of authenticity, with gender identity being one of the only realms where this possibility might be fulfilled (Bialystok, 2009, 2011, 2013, personal communication). Still, feminist poststructural theorist, Joan Scott (1991) articulates how relying on notions of experience "not only makes individuals the starting point of knowledge, but that also naturalizes categories such as man, woman, black, white, heterosexual and homosexual by making them characteristics of individuals" (p. 782). Thus, if a rigorous analysis of authenticity in personal identity demands such a 'metaphysics of substance', it could be contentious from a poststructural perspective to be asking questions of authenticity (Bialystok, 2014, personal communication). ${ }^{10}$

\section{In Conclusion}

For many effeminate or femme gay men, denying their sense of authenticity and gendered personhood holds great ramifications within socio-cultural conditions that glorify hegemonic conceptions of masculinities. Challenging an individual's respective gender or sex identity can carry great psychological impacts, as can existing in a climate in which one's sense of gendered self cannot be expressed or authenticated. The current gendered conditions of mainstream gay men's communities require further academic investigation to bring a greater awareness to the structures of misogyny and femmephobia that denigrate and pathologize expressions of femininity within men (Bergling, 2002; Eguchi, 2011; Miller, 2015, 2018; Miller \& Behm-Morawitz, 2016; Sánchez, Greenberg, Liu \& Vilain, 2009). The perseverance of effeminate gay men despite sociocultural conditions that devalue their gendered selves and identities brings forward further conversations regarding the ethics of authenticity and personal identity, as well as the necessity of supporting the development of gender identity and expression in young boys and adolescents. As delineated, many young gay men quickly alter their respective gender expression upon entering mainstream gay communities and cultures by conforming to hyper masculinized norms for emotional detachment and athletic embodiment (Sánchez et al., 2009; Taywaditep, 2002). This defeminization presents identity-based challenges for many gay men as they must either conform to masculinized expectations to feel a sense of belonging within many gay spaces, or remain authentic to their sense of gendered self, but feel 'othered' within many gay spaces and communities (Bergling, 2002; Martino, 2006; Miller \& Behm-Morawitz, 2016; Miller, 2018).

\footnotetext{
${ }^{10}$ For a detailed conversation on the ethics of authenticity and personal identity, and humanist versus existentialist approaches to authenticity, please see Bialystok (2009, 2011, 2014, 2017). I agree with Bialystok's (2013) assertion that gender identity might be the only realm where there is a metaphysical possibility of being "true to yourself" in personal identity while acknowledging how this can be dangerous when applied to other identities. Bialystok (2014) is skeptical of any notion of fulfilling a complete metaphysical account of authenticity (also see Bialystok \& Kukar, 2018).
} 
Addressing the discrimination and shame many gender-nonconforming young boys face in childhood can assist in creating more inclusive queer communities as adults (Downs, 2012).

While discourses of authenticity have been criticized, even in the case of gender identity and authenticity (Lee, 2012; Hord, 2017), current modernist imaginations of authenticity still commonly link honoring one's sense of gendered self with a 'true' or 'real' identity (Bialystok, 2017). With authenticity being embedded in Enlightenment-based discourses and Western liberal theorizing, it is possible for authenticity to become subsumed within uncritical individualism and narcissism (Bialystok 2011, 2015, 2017). Bialystok (2011) notes how "the assumption that we have at any given moment a single, true identity, which can either be simply reflected or denied in our conduct, assumes a level of metaphysical essentialism and stagnancy in personal identity that is counterintuitive" (p. 221). Considering the postmodern and poststructural critiques of the Enlightenment-based ' $I$ ' from liberal philosophical traditions, authenticity and theorizations of personal identity fall within such traditions. However, strands of poststructural and queer theories have been critiqued for attempting to deconstruct a sovereign subject, while simultaneously reifying a privileged white, masculinist, gay man as the centre of its theoretical focus (Halberstam, 2005), and for invalidating transgender and gender-nonconforming individuals' lived experiences (Monro, 2005; Namaste, 2000). Regarding self-identification, Bialystok (2011) iterates how "although our choices of identification are limited and sometimes prescribed without our consent, we forge an identity on the basis of some internal response to our circumstances" (p. 224). Thus, in Bialystok's view, while the choices one can make to identify can be discursively constituted, there is a sense of individual consciousness that chooses to identify a certain way.

Cumulatively, it can be argued that effeminate or femme gay men fit well within Bialystok's (2013) theorization of authenticity in sex/gender identity, with debates emerging regarding theorizing metaphysical essentialism in authenticity in personal identity (Bialystok, 2009), particularly as it pertains to liberal humanism, and poststructural critiques of identity, experience, and authenticity. Still, there are important considerations to be made regarding the identity-based challenges that effeminate gay men experience within mainstream gay communities, and the gender-based discrimination and policing many men are exposed to. Bialystok's important work and theorization in the realm of gender identity illustrates how calls to personal authenticity and a sense of 'self' are important tools to forward political activism and awareness for gender-based discrimination. Due to the complexities of the gendered dynamics within queer communities, many are unaware of the imbued nature of femmephobia within the fabrics of gay men's communities. Thus, for those who work with LGBTQ+ youth, it is necessary to understand the pressures many gay youth experience to "defeminize" (Taywaditep, 2002) upon entering gay communities and the widespread nature of femmephobia. Clearly, whether identity and authenticity are relevant is very important as it pertains to the lived realities of gender diversity and continual struggles for gender equality.

\section{Acknowledgements}

I would like to sincerely thank Dr. Lauren Bialystok for her important work and thoughts towards this manuscript, as well as my friends and colleagues, Dr. Rhea Ashley Hoskin, Harrison Oakes, and Evan Vipond. I appreciate everyone who provided thoughts and feedback towards this publication and hope to bring more awareness to issues of femmephobia and misogyny in gay men's communities. 
Davies

\section{References}

Airton, L. (2009). From sexuality (gender) to gender (sexuality): The aims of anti-homophobia education. Sex Education, 9(2), 129-139.

Alexander, J. (2016). Fellow gay men, stop glorifying toxic ideals of masculinity. Huffington Post. Retrieved from https://www.huffingtonpost.ca/jeremy-alexander93/lgbtq-broculture_b_13154426.html

Alvarez, E. (2008). Muscle boys: Gay gym culture. New York, NY: Routledge.

Barry, B., \& Martin, D. (2016). Gender rebels: Inside the wardrobes of young gay men with subversive style. Fashion, Style \& Popular Culture, 3(2), 225-250.

Bauer, K. (2017). To be or not to be authentic. In defence of authenticity as an ethical ideal. Ethical Theory and Moral Practice, 20(3), 567-580.

Bergling, T. (2002). Sissyphobia: Gay men and effeminate behavior. New York, NY: Harrington Park Press.

Bergling, T. (2006). Sissyphobia and everything after. In C. Kendall \& W. Martino (Eds.), Gendered outcasts and sexual outlaws: Sexual oppression and gender hierarchies in queer men's lives (pp. 27-34). London, UK: Routledge.

Bialystok, L. (2009). Being your self: Identity, metaphysics, and the search for authenticity (Unpublished doctoral dissertation). University of Toronto, Toronto, ON, Canada.

Bialystok, L. (2011). Refuting Polonius: Sincerity, authenticity, and 'shtick'. Philosophical Papers, 40(2), 207-231.

Bialystok, L. (2013). Authenticity and trans identity. In R. S. Stewart (Ed.), Talk about sex: A multidisciplinary discussion (pp.122-145). Sydney, NS: Cape Breton University Press.

Bialystok, L. (2014). Authenticity and the limits of philosophy. Dialogue: Canadian Philosophical Review/Revue canadienne de philosophie, 53(2), 271-298.

Bialystok, L. (2015). Should teachers be authentic?. Ethics and Education, 10(3), 313-326.

Bialystok, L. (2016). Transgender inclusion in single-sex competition: The case of beauty pageants. 42(3), Social Theory and Practice, 605-635. 
Davies

Bialystok, L. (2017). Authenticity in education. In Oxford Research Encyclopedia of Education. DOI: 10.1093/acrefore/9780190264093.013.168.

Bialystok, L., \& Kukar, P. (2018). Authenticity and empathy in education. Theory and Research in Education, 16(1), 23-39.

Bishop, C. J., Kiss, M., Morrison, T. G., Rushe, D. M., \& Specht, J. (2014). The association between gay men's stereotypic beliefs about drag queens and their endorsement of hypermasculinity. Journal of Homosexuality, 61(4), 554-567.

Blair, K. L., \& Hoskin, R. A. (2015). Experiences of femme identity: Coming out, invisibility and femmephobia. Psychology \& Sexuality, 6(3), 229-244.

Blair, K. L., \& Hoskin, R. A. (2016). Contemporary understandings of femme identities and related experiences of discrimination. Psychology \& Sexuality, 7(2), 101-115. https://doi.org/10.1080/ 19419899.2015.1053824.

Butler, J. (1990). Gender trouble. London, UK: Routledge.

Cadwell, S. (2009). Shame, gender, and sexuality in gay men's group therapy. Group, 33(3), 197-212.

Césaire, A. (2001). Discourse on colonialism. New York, NY: New York University Press.

Connell, R. W. (1992). A very straight gay: Masculinity, homosexual experience, and the dynamics of gender. American Sociological Review, 57(6), 735-751.

Crossley, N. (2006). Reflexive embodiment in contemporary society: The body in late modern society. London, UK: McGraw-Hill Education.

Degrazia, D. (2004). Prozac, enhancement, and self creation. In E. Elliot, \& T. Chambers (Eds.), Prozac as a way of life (pp. 33-47). Chapel Hill, NC: University of North Carolina Press.

Downs, A. (2012). The velvet rage: Overcoming the pain of growing up gay in a straight man's world. Boston, MA: Lifelong Books.

Eguchi, S. (2011). Negotiating sissyphobia: A critical/interpretive analysis of one "femme" gay Asian body in the heteronormative world. The Journal of Men's Studies, 19(1), 37-56.

Fischgrund, B. N., Halkitis, P. N., \& Carroll, R. A. (2012). Conceptions of hypermasculinity and mental health states in gay and bisexual men. Psychology of Men \& Masculinity, 13(2), 123-135.

Foucault, M. (1970) The Order of Things: An Archeology of the Human Sciences. New York: Vintage. 
Davies

Gaikwad, V. (2015). Why effeminate gays are fabulous. The Advocate. Retrieved from https://www.advocate.com/commentary/2015/12/22/why-effeminate-gays-are-fabulous.

Green, R. (1979). 'Sissies' and 'tomboys'. SIECUS Report, 7(3), 1-15.

Griffiths, S., Murray, S. B., Dunn, M., \& Blashill, A. J. (2017). Anabolic steroid use among gay and bisexual men living in Australia and New Zealand: Associations with demographics, body dissatisfaction, eating disorder psychopathology, and quality of life. Drug and alcohol dependence, 181, 170-176.

Halberstam, J. (2005). Shame and white gay masculinity. Social Text, 23(3-4 (84-85)), 219-233.

Hale, S. E., \& Ojeda, T. (2018). Acceptable femininity? Gay male misogyny and the policing of queer femininities. European Journal of Women's Studies, 25(3), 310-324.

Halkitis, P. N., Moeller, R. W., \& DeRaleau, L. B. (2008). Steroid use in gay, bisexual, and nonidentified men-who-have-sex-with-men: Relations to masculinity, physical, and mental health. Psychology of Men \& Masculinity, 9(2), 106-115.

Harry, J. (1983). Defeminization and adult psychological well-being among male homosexuals. Archives of Sexual Behavior, 12(1), 1-19.

hooks, b. (1992). Black looks: Race and representation. Boston, MM: South East Press.

Hord, L. (2017). The drive of queer exceptionalism: Transgender authenticity as queer aesthetic. University of Western Ontario 2017 Undergraduate Awards. Retreived from https://ir.lib.uwo.ca/cgi/viewcontent.cgi?article=1008\&context=undergradawards_2017.

Hoskin, R. A. (2017). Femme theory: Refocusing the intersectional lens. Atlantis: Critical Studies in Gender, Culture \& Social Justice, 38(1), 95-109.

Hutson, D. J. (2010). Standing out/fitting in: Identity, appearance, and authenticity in gay and lesbian communities. Symbolic Interaction, 33(2), 213-233.

Kuhl, D., \& Martino, W. (2018). 'Sissy' boys and the pathologization of gender non-conformity. In S. Talburt (Ed.), Youth sexualities: Public feelings and contemporary cultural politics (Vol. 1, pp. 31-60). Santa Barbara, CA: Praeger.

Lather, P. (2000). Against empathy voice and authenticity. Kvinder, Kon \& Forskning, 4. Tilgængelig hos: https://tidsskrift.dk/KKF/article/view/28384 (Set: 31juli2018).

Lee, M. C. (2012). The paradox of authenticity: The depoliticization of trans identity. (Master's Thesis). The Ohio State University, City, Ohio. 
Davies

Levine, M. P. (1998). Gay macho: The life and death of the homosexual clone. New York, NY: New York University Press.

Martino, W. (2000). Policing masculinities: Investigating the role of homophobia and heteronormativity in the lives of adolescent school boys. The Journal of Men's Studies, 8(2), 213-236.

Martino, W. (2006). Straight-acting masculinities: Normalization and gender hierarchies in gay men's lives. In C. Kendall, \& W. Martino (Eds.), Gendered outcasts and sexual outlaws (pp. 35-60). London, UK: Routledge.

Miller, B. (2015). "They're the modern-day gay bar": Exploring the uses and gratifications of social networks for men who have sex with men. Computers in Human Behavior, 51, 476-482.

Miller, B. (2018). Textually presenting masculinity and the body on mobile dating apps for men who have sex with men. The Journal of Men's Studies, 26(3), 305-326.

Miller, B., \& Behm-Morawitz, E. (2016). "Masculine guys only": The effects of femmephobic mobile dating application profiles on partner selection for men who have sex with men. Computers in Human Behavior, 62, 176-185.

Monro, S. (2005). Beyond male and female: Poststructuralism and the spectrum of gender. International Journal of Transgenderism, 8(1), 3-22.

Namaste, V. (2000). Invisible lives: The erasure of transsexual and transgendered people. Chicago, IL: University of Chicago Press.

Oshana, M. (2007). Autonomy and the question of authenticity. Social Theory and Practice, 33(3), 411-429.

Parfit, D. (1971). Personal Identity. Philosophical Review 80, 3-27.

Parfit, D. (1984). Reasons and persons. Oxford, UK: Oxford University Press

Pascoe, C. J. (2011). Dude, you're a fag: Masculinity and sexuality in high school. Berkerley, CA: University of California Press.

Prosser, J. (2006). Judith Butler: Queer feminism, transgender, and the transubstantiation of sex. In S. Strker \& S. Whittle (Eds.), The transgender studies reader (pp. 273-296). Routledge.

Reisert, J. R. (2000). Authenticity, justice, and virtue in Taylor and Rousseau. Polity, 33(2), 305330. 
Davies

Ricoeur, P. (1992). Oneself as another. Chicago, IL: University of Chicago Press.

Rose, N. (1998). Inventing our selves: Psychology, power, and personhood. Cambridge, UK: Cambridge University Press.

Rousseau, J.-J. (2006). Autobiographical, scientific, religious, moral, and literary writings. New Hampshire: University Press of New England.

Rousseau, J.-J. (1903/2012). The Confessions of Jean-Jacques Rousseau: Complete (W. C. Mallory, Trans.). Auckland, NZ: The Floating Press.

Sánchez, F. J., \& Vilain, E. (2012). "Straight-acting gays": The relationship between masculine consciousness, anti-effeminacy, and negative gay identity. Archives of Sexual Behavior, 41(1), 111-119.

Sánchez, F. J., Greenberg, S. T., Liu, W. M., \& Vilain, E. (2009). Reported effects of masculine ideals on gay men. Psychology of Men \& Masculinity, 10(1), 73-87.

Scott, J. W. (1991). The evidence of experience. Critical Inquiry, 17(4), 773-797.

Sedgwick, E. K. (1994). How to bring your kids up gay: The war on effeminate boys across genders, across sexualities. In Tendencies (pp. 154-166). Location: Duke University Press.

Serano, J. (2012) Reclaiming femininity. In A. Enke (Ed.). Transfeminist perspectives in and beyond transgender and gender studies (pp. 170-184). Philadephia, PA: Temple University Press.

Serano, J. (2007/2016). Whipping girl: A transsexual woman on sexism and the scapegoating of femininity. Hachette, UK.

Stoller, R. J. (1968). Male childhood transsexualism. Journal of the American Academy of Child Psychiatry, 7(2), 193-209.

Taywaditep, K. J. (2002). Marginalization among the marginalized: Gay men's anti-effeminacy attitudes. Journal of Homosexuality, 42(1), 1-28.

Taylor, A. (2018). "Flabulously" femme: Queer fat femme women's identities and experiences. Journal of Lesbian Studies, 22(4), 459-481.

Taylor, C. (1991). The ethics of authenticity. Cambridge, MA: Harvard University Press.

Tosh, J. (2016). Psychology and gender dysphoria: Feminist and transgender perspectives. Emeryville, CA: Seal Press. 
Davies

Titchkosky, T. (2014). Monitoring disability: The question of the 'human' in human rights projects. In M. Gill \& C. J. Schlund-Vials (Eds.), Disability, human rights and the limits of humanitarianism (pp. 119-135). Routledge.

Van Inwagen, P. (2007). Metaphysics. In E. N. Zalta (Ed.), The Stanford encyclopedia of philosophy (Fall 2007 Edition). Retrieved from http://plato.stanford.edu/archives/fall2007/entries/metaphysics.

Varga, S. (2014). Authenticity. In Stanford Encyclopedia of Philosophy. Retrieved from https://plato.stanford.edu/entries/authenticity/.

Vipond, E. (2015). Resisting transnormativity: Challenging the medicalization and regulation of trans bodies. Theory in Action, 8(2).

Wray, T. (2003). The queer gaze. Retrieved from https://epub.uniweimar.de/opus4/frontdoor/deliver/index/docId/1267/file/wray_pdfa.pdf.

Wimberley, J. (2015). "Men are gay because they like men”: Femmephobia and sizeism in the gay community. Huffington Post. Retrieved from http://www.huffingtonpost.com/nathanmanske/men-are-gay-because-they-_b_7888138.html.

Wynter, S. (2003). Unsettling the coloniality of being/power/truth/freedom: Towards the human, after man, its overrepresentation-An argument. CR: The New Centennial Review, 3(3), 257-337. 